\title{
Comparison of fatigue crack propagation behaviour in two steel grades S235, S355 and a steel from old crane way
}

\author{
Stanislav Seitl ${ }^{1,2 *}$, Pavel Pokorný ${ }^{1}$, Petr Miarka ${ }^{1,2}$, Jan Klusák ${ }^{1}$, Zdeněk Kala $^{2}$ and Ludvík \\ Kunz $^{1}$ \\ ${ }^{1}$ Institute of Physics of Materials, ASCR, v. v. i., Zizkova 22, 616 62, Brno, Czech Republic \\ ${ }^{2}$ Faculty of Civil Engineering, Brno University of Technology, Veveri 331/95, 60200 Brno, Czech \\ Republic
}

\begin{abstract}
Utilization of various steel grades in civil engineering allows designing bridges, bridge elements or simple structures according to their fracture mechanical properties. The service intervals of structures, which are going to be in use for a long time, cannot be calculated only on the basis of tensile and brittle fracture properties but also on the knowledge of the resistance to the fatigue crack growth. This contribution presents a comparison of the fatigue behaviour of two modern steel grades S235 J2, S355 J2 and a steel extracted from an old crane way. The comparison of these steel grades is done by fatigue crack propagation tests (the results of the experimental tests are described using concept of the stress intensity factor range $\Delta K$ ). The fatigue properties are discussed and recommendations for the use of the steels are stated.
\end{abstract}

\section{Introduction}

The key parameters for design and manufacturing of civil engineering structures are structural integrity, damage tolerance, reduction of structural weight, and manufacturing cost. For application on new structures, a complex experimental campaign has to be performed before the structures are going to be built. On the other hand it is rather difficult to estimate the remaining fatigue life of structural elements, which are already in use, due to lack of knowledge of used materials and their mechanical characteristics. Similarly, the load history together with structural changes due to repairs or strengthening are hardly to find within whole structures' service life time (e.g. the last hundred years).

In many ways, steel bridges exhibit very similar problems like structures (in our case crane) in industrial facilities [1]. The fatigue assessment guideline for the estimation of the remaining fatigue life of steel bridges [2] is a useful tool commonly applied for condition assessment that complements bridge management systems.

The aim of this contribution is to compare experimentally obtained fatigue crack growth rates of long fatigue cracks in two steel grades S235 J2, S355 J2 and a steel extracted from an old crane way and to quantify the influence of selected properties on fatigue crack

*Corresponding author: seitl@ipm.cz, seitl.s@fce.vutbr.cz 
resistance. The fatigue crack propagation is characterized by means of crack growth curves experimentally determined on compact tension (CT) specimens. The experimentally obtained results are discussed.

\section{Materials and experimental data processing procedure}

\subsection{Materials}

The chemical composition of steels S235 J2 and S355 J2 is specified in standard EN 100252:2004 [3] and it is presented in Tab.1 together with an information about chemical composition of the old crane way steel obtained by chemical analysis performed by EDS on SEM TESCAN LYRA. Chemical composition of the modern S235 J2, S355 J2 was verified by producer and it is in agreement with the standard presented in this paper.

Table 1. Chemical composition of the used steels in wt. \% determined grades according to EN 100252:2004 standard and obtain from by chemical analysis by EDS technique.

\begin{tabular}{|c|c|c|c|}
\hline Steel grade & S235 J2 & S355 J2 & Old crane steel \\
\hline C (max. \%) & 0.17 & 0.2 & 0.1 \\
\hline Mn (max. \%) & 1.4 & 1.6 & 0.5 \\
\hline Si (max. \%) & - & 0.55 & - \\
\hline P (max. \%) & 0.03 & 0.03 & - \\
\hline S (max. \%) & 0.03 & 0.03 & - \\
\hline Cu (max. \%) & 0.55 & 0.55 & - \\
\hline CEV (max. \%) & 0.35 & 0.47 & - \\
\hline Other (max. \%) & - & - & - \\
\hline
\end{tabular}

The microstructure of the three used materials is shown in Fig.1. The specimen surface was etched with $2 \% \mathrm{Nital}$ and the light optical microscope was used for structure imaging.

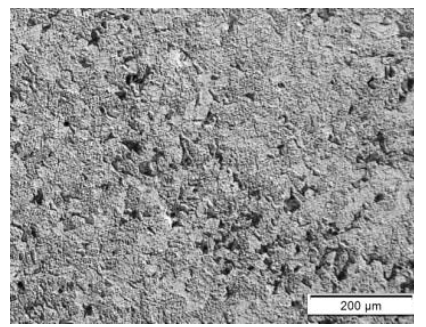

a) S235 J2

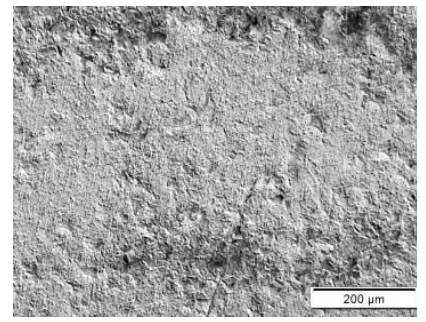

b) $\mathrm{S} 355 \mathrm{~J} 2$

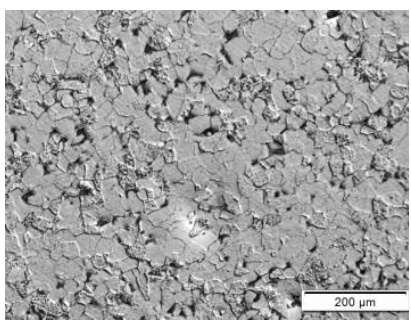

c) Old crane steel

Fig. 1. Structure of the S235 J2, S355 J2 and the old crane steel etched with 2\% Nital, light optical microscope. 
The average grain size with standard deviation estimated with linear intersection method was 18,18 and $21 \mu \mathrm{m}$ for the S235 J2, S355 J2 and the old crane way steel, respectively. Mechanical properties of the studied materials determined according to EN 10002-1 standard [4] are summarized in Tab. 2. The tensile strengths are significantly higher for S235 and S355 than the code value.

Table 2. Mechanical properties of S235 J2, S355 J2 and steel from the old crane way mean values with standard deviation.

\begin{tabular}{|c|c|c|c|}
\hline Steel grade & $\mathbf{S 2 3 5} \mathbf{~ J 2}$ & $\mathbf{S 3 5 5} \mathbf{~ J 2}$ & Old crane steel \\
\hline $\begin{array}{c}\text { Young's modulus } \\
{[\mathrm{GPa}]}\end{array}$ & $208.2 \pm 4.1$ & $205.4 \pm 7.4$ & $206.3 \pm 6.2$ \\
\hline $\begin{array}{c}\text { Yield stress } \\
{[\mathrm{MPa}]}\end{array}$ & $276.87 \pm 0.31$ & $381.94 \pm 6.22$ & $271.2 \pm 2.46$ \\
\hline $\begin{array}{c}\text { UTS } \\
{[\mathrm{MPa}]}\end{array}$ & $423.86 \pm 1.49$ & $554.41 \pm 1.62$ & $439.28 \pm 0.49$ \\
\hline $\begin{array}{c}\text { Elongation at break } \\
{[\%]}\end{array}$ & $21.99 \pm 0.22$ & $34.22 \pm 1.54$ & $18.49 \pm 0.23$ \\
\hline $\begin{array}{c}\text { Poisson's ratio } \\
{[-]}\end{array}$ & 0.3 & 0.3 & 0.3 \\
\hline
\end{tabular}

\subsection{Experimental data processing procedure}

The fatigue crack growth experiments were carried out at a computer-controlled testing machine (Amsler $2 \mathrm{HFP}$ with maximal load $20 \mathrm{kN}$ ). Tests were conducted under load control. The stress ratio $R=P_{\min } / P_{\max }=0.1$, where $P_{\min }$ and $P_{\max }$ refer to the minimum and maximum load of a sinusoidal wave in each cycle. The controlled values for temperature and relative humidity were $23 \pm 2{ }^{\circ} \mathrm{C}$ and $50 \%$, respectively. The load frequency used for the tests varied from 100 (for the shortest cracks) to $60 \mathrm{~Hz}$ (for the longest cracks).

The fatigue crack growth resistance was characterized by Paris' law [5], se more about fatigue behavior in e.g. [6], i.e. the dependence of the crack growth rate on the applied stress intensity factor range $\Delta K$ :

$$
\frac{d a}{d N}=C(\Delta K)^{m}
$$

where $C$ and $m$ are the material constants and $\Delta K$ is the stress intensity factor range given by ASTM [7]

$$
\Delta K=\left(\sigma_{\max }-\sigma_{\min }\right) \sqrt{\pi a} Y(a / W),
$$

where $\sigma_{\max }$ and $\sigma_{\min }$ are the maximum and minimum applied stresses, $a$ is the crack length and $Y$ is the geometry function depended on the specimen geometry [8].

For the comparison of fatigue crack growth resistance of studied materials, the compact tension (CT) specimens according to the ASTM E647 [7] Standard were selected, see Fig. 2. The tested CT specimens had dimensions: $L=62.5 \mathrm{~mm}, W=50 \mathrm{~mm}, B=10 \mathrm{~mm}, a_{\mathrm{n}}=12.5$ $\mathrm{mm}, H / 2=30 \mathrm{~mm}$ and the angle $\beta_{1}=60^{\circ}$. The experimentally determined crack length was the average of measurement performed on both sides of the CT specimens. The crack length was measured optically by using of two CCD cameras. The initial crack (notch) was oriented perpendicularly to the rolling direction. It is expected that rolling direction corresponds to purposed direction of loading (fatigue cracks initiate and grow perpendicularly to the loading direction), see [9]. Note that previous work on S355 [10, 11, 12] S355 J2 [13] or S355 J0 
$[14,15]$ showed that the fatigue crack propagation rate seems to be independent of the rolling direction and resulting microstructure.

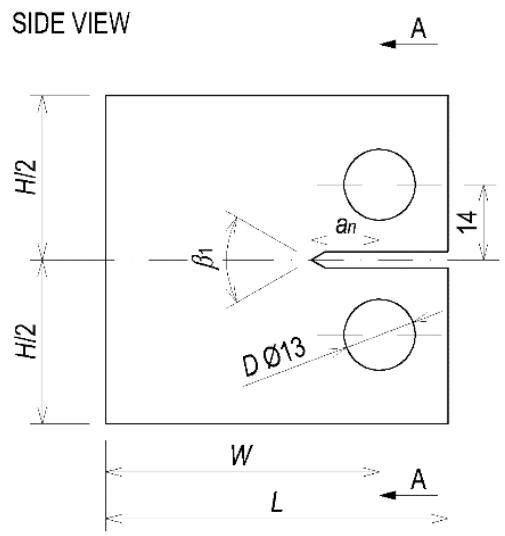

SECTION A-A

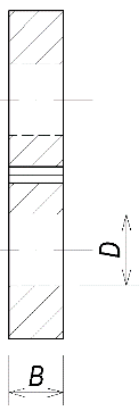

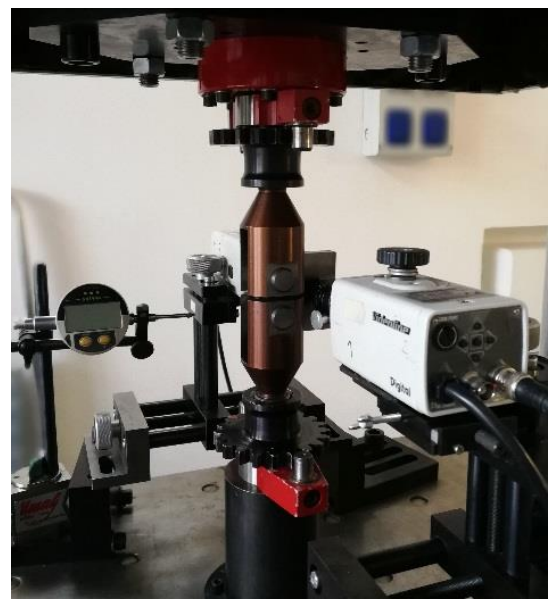

Fig. 2. Geometry of the compact tension (CT) specimen and experimental setup.

\section{Experimental results and discussion}

On the base of obtained results, obtained and statistically evaluated fracture mechanical properties could be important for sensitivity analysis of civil engineering steel structures under fatigue load, when the properties from Paris' law are utilized as input parameters [1619]. Knowledge on the fatigue crack growth rate is necessary to ensure safety service during the operation of the old crane and to compare the properties of the old material with the new ones. The old crane steel was loaded for years with a loading history that can be predicted, but not known precisely [20]. The diagonal structural element, from which the material was taken, was found with no fatigue cracks. Thus we consider the previous loading only below the fatigue limit of the material. Moreover, the specimens for fatigue crack growth rate measurements were milled and polished, where the surface (with potential microcracks) of the material was machined out. These facts lead us to the conclusion that the previous loading of the material has no significant influence on current measurements and omitting of the previous loading is justified.

Table 3. Constants of Paris' law for the S235, S355 and steel of old crane way for $R=0.1$.

\begin{tabular}{|c|c|c|c|}
\hline Steel grade & $\mathbf{S 2 3 5} \mathbf{J 2}$ & $\mathbf{S 3 5 5} \mathbf{~ J 2}$ & Old crane steel \\
\hline $\begin{array}{c}C(\mathrm{~d} a / \mathrm{d} N \text { in } \\
m m / c y c l e)\end{array}$ & $2.0 \mathrm{e}-9$ & $1.0 \mathrm{e}-8$ & $5.0 \mathrm{e}-10$ \\
\hline$m$ & 3.26 & 2.71 & 3.59 \\
\hline $\mathrm{R}^{2}$ & 0.91 & 0.99 & 0.90 \\
\hline
\end{tabular}

In particular the fatigue crack growth behaviour of particular materials is compared for the stress ratio $R=0.1$, Fig. 3. Finally, comparison with data available in the literature is performed. The crack growth rates, $\mathrm{d} a / \mathrm{d} N$, are plotted as a function of the stress intensity factor range, $\Delta K$. The crack growth rates were computed using the seven point incremental 
polynomial technique, as required in the ASTM E647 [7] standard. The experimental crack propagation data were correlated with Paris' law, since only the crack propagation regime II was covered by the present experimental research.

Table 3 summarizes the constants of the Paris' law for the three steels for the stress ratio $R=0.1$. The table also includes the coefficients resulting from the fitting the Eq. 1 to the experimental data. All determination coefficients are above 0.90 , which represents very high correlations. The slope of the crack growth rate curve on log-log scale denotes the value of the exponent $m$ and is typically found for metallic materials to lie in the range from 2 to 4 [6,21]; for all steels investigated $m$ lays in this interval. The crack growth data of the S355 steel exhibit lower scatter $\mathrm{R}^{2}=0.99$ than that for the $\mathrm{S} 235$ and the steel of the old crane way $\left(\mathrm{R}^{2} \approx 0.9\right)$, which means higher quality of the $\mathrm{S} 355$ steel with respect to the both mild steels

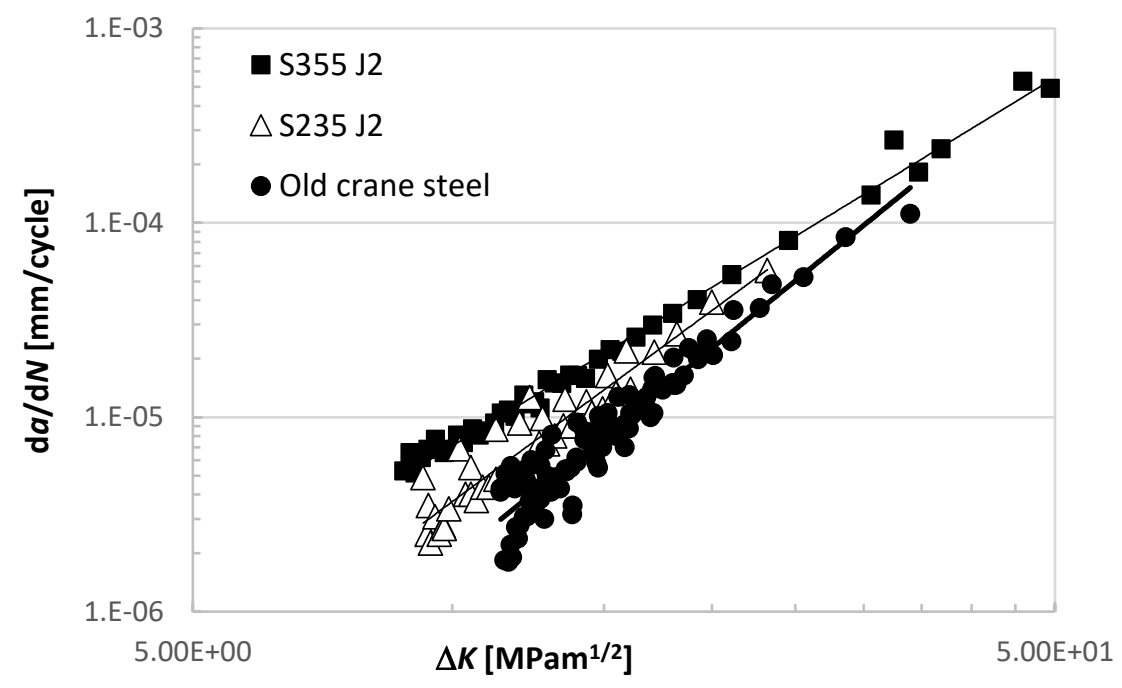

Fig. 3. Fatigue crack growth curves for S355J2 S235J2 and old crane way steel.

Fig. 3 compares the fatigue crack propagation curves for the three steel grades under investigation. For the same geometry and same test conditions, the results show marked differences between the values of fatigue crack propagation rates for the same value of the stress intensity factor range. The difference increases with decreasing $\Delta K$ value. These results may be justified by the finer grain of the S235 and S355 steels (in comparison with the old crane way steel) which facilitates the fatigue crack propagation.

It is interesting to note that fatigue crack propagation rates increase with increasing yield strength of steels, similar like reported by Jesus [10]. This implies that there is no advantage of using the S355 steel for structural components whose fatigue life is dominated by crack propagation, rather than crack initiation. This means that from fatigue crack propagation point of view it is more advantageous to use the S235 steel for manufacturing of structural components.

\section{Conclusion}

Growth of long fatigue cracks was experimentally investigated and evaluated in two standard steel grades (S235, S355) and a steel from an old crane way: 
- The fatigue crack growth rates in S355 and S235 steels are higher than in steel from old crane way under the same stress intensity factor range, which means that the old steel is more resistant to the growth of long fatigue cracks.

- The results show that it is preferable to use the S235 steel for replacement of the structural components in the cases where the fatigue crack growth is the decisive parameter for the service life.

The authors gratefully acknowledge the financial support by the Czech Science Foundation under the contract No. 17-01589S.

\section{References}

1. XW. Ye, YH .Su, JP. Han,. Math Probl Eng, 2014, 1-13 (2014)

2. J. Vičan, J. Gocál, J. Odrobiňák, P. Koteš,. Procedia Eng; 156, 507-514. (2016)

3. EN 10025-2:2004 European Standard Hot rolled products of structural steels - Part 2: Technical delivery conditions for non-alloy structural steels

4. EN 10002-1 METALLIC MATERIALS - TENSILE TESTING - Part 1: Method of test at ambient temperature, February (2002)

5. PC. Paris, F. Erdogan, Journal of Basic Engineering, 85, 528-534 (1963)

6. M. Klesnil, P. Lukáš, Fatigue of Metallic Materials (Elsevier, 270, 1992)

7. ASTM E647-15e1, Standard test method for measurement of fatigue crack growth rates. ASTM International (2015)

8. TL. Anderson, Fracture Mechanics: Fundamentals and applications, (Taylor and Francis, UK. 2005)

9. P. Lehner, M. Krejsa, P. Pařenica, V. Křivý, J. Brožovský, Inter. Jour. Fat., 128, 105190 (2019)

10. A. M. P. de Jesus, R. Matos, B.F.C. Fontoura, C. Rebelo, L. Simoes da Silva, M. Veljkovic, J. Const. St. Res. 79, 140-150 (2012)

11. J. Lewandowski, D. Rozumek, Theor. App. Frac. Mech., 86 352-350 (2016)

12. D. Rozumek, Z. Marciniak. G. Lesiuk, J. A. F. O. CORREIA, Procedia Structural Integrity. 5 896-903 (2017).

13. O. Adedipe, F. Brennan, A. Kolios, Renewable and Sustainable Energy Reviews. 61, 141-154 (2016)

14. S. Seitl, P. Miarka, P. Pokorný, S. Fintová, J. Klusák, Proceedings, 2, 470 (2018)

15. S. Seitl, P. Miarka, J. Klusak, S. Fintova, L. Kunz, Key Engin. Mat., 784 91-96 (2018).

16. Z. Kala, AIP Conference Proceedings, 1863,480004 (2017).

17. Z. Kala, A. Omishore, Inter. J. of Math. and Comp. in Sim. 10, 294-301 (2016).

18. M. Krejsa, Z. Kala, S. Seitl, Procedia Engineering 142, 145-152 (2016).

19. M. Krejsa, L. Koubová, J. Flodr, J. Protivinsky, Q.T. Nguyen, , Frat. ed Int. Strut. 11(39), 143-159 (2017).

20. P. Lehner, M. Krejsa, P. Pařenica, V. Křivý, J. Brožovský, Inter. J. of Fat., 128, 1-9, article number 105190 (2019).

21. S. Suresh, Fatigue of Materials (Cambridge University Press, 2012). 